\title{
THE PHOSPHORESCENCE OF SOME INORGANIC
}

SALTS

\section{BY JOHN ANDERSON WILKINSON}

That there is some relation between phosphorescence or fluorescence and chemical action has been shown in a number of cases.

The phosphorescence of phosphorus has been known to be due to oxidation for some time and Ewan ${ }^{1}$ has shown the relation between the phosphorescence and the pressure of the oxygen, the limits of the former depending upon the latter. $^{2}$

The phosphorescence and fluorescence of the salts of quinine have been shown to be due to hydration and dehydration. Kalähne ${ }^{3}$ and Le Bon ${ }^{4}$ have shown that if quinine sulphate is heated suddenly, above $100^{\circ}$, there is a faint phosphorescence which lasts for only a short time. On cooling, the same thing can be seen. If the salt is allowed to cool in the absence of water vapor no luminescence is observed. This shows that the hydration and dehydration of the salt give out light.

Miss Gates ${ }^{5}$ worked on the ionization of gases and on the change of conductivity caused by quinine sulphate when phosphorescing as a result of heating. She showed that the light is due to a change in the molecule and not to its giving off charged particles as a radioactive body does. This agrees with Le Bon's experiments.

Villard, ${ }^{8}$ in his work with the $\mathrm{X}$-rays, found that the cathode rays turned glass black, due to the setting free of lead. If the cathode rays are cut off by a piece of aluminum which is transparent to the $\mathrm{X}$-rays but not to the cathode

${ }^{1}$ Ewan: Zeit. phys. Chem., I6, 315 (1898).

${ }^{2}$ Corne: Jour, pharm. Chim. [5], 6, I7.

${ }^{3}$ Kalähne: Drude's Ann., I 8, 450 (1905).

4 Le Bon: Comptes rendus, I30, 891 (1900)

${ }^{5}$ Gates: Pliys. Rev., I9, I35 (1904).

\& Villard: Comptes rendus, 129, 882 (I899). 
rays, the glass is turned riolet. This, he says, is due to the presence of manganese in the glass. P. Curie and Sklodowski Curie ${ }^{1}$ found that ozone was to be detected in glass vessels containing radioactive salts and that these salts affect the glass, turning it deep violet, especially where the salt is in contact with the glass. This is true even when the glass contains no lead.

Barium platinocyanide turns dark under continued exposure to excitation but regains its original color when exposed to sunlight.

Wiedemann and Schmidt" have investigated the fluorescence, phosphorescence and thermo-phosphorescence of a large number of simple salts and solid solutions in the cathode rays. They divide the simple salts into three groups.

I. Those which show fluorescence and phosphorescence and also decomposition under influence of cathode rays.

II. Those which show fluorescence and phosphorescence but no apparent decomposition.

III. Those which show no luminescence.

Under the first group are placed the halogen salts of the alkali metals, silver, mercury and lead. In these the color of the fluorescence and phosphorescence is often different. This, they say, is due to the fluorescence being caused by the decomposition of the salt with the formation of the subchloride, bromide or iodide, while the phosphorescence is due to the change back into the original compound or to the decomposition of the sub-salt. Further, the residue after the action of the cathode rays is always colored, varying from blue to brown or black, depending both upon the nature of the salt and the duration of the cathode discharge.

Under the second group are placed the sulphates of the alkalies, salts of the alkaline earth and magnesium groups and some of the heavier metals. These differ from the first group only in showing no colored residue after the action of

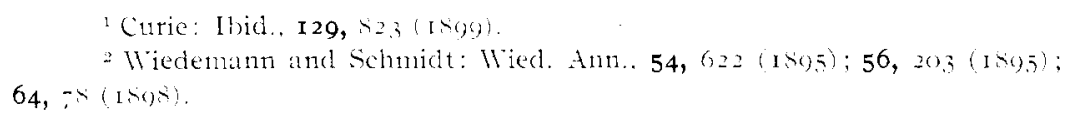


the cathode rays. However, some of these, after long exposure, do show a slight decomposition and so the distinction between the first and second group is one of degree only.

Wiedemann and Schmidt say that under the cathode rays the color of the phosphorescence of the salts of any metal is independent of the nature of the acid radical. All salts of the same metal give the same color, differing only in intensity. This is illustrated with cadmium and uranium salts, the former giring vellow phosphorescence and the latter green.

Under the third group they place all the rest of the simple salts which they tried and found no light effect.

Goldstein ${ }^{1}$ tried the effect of the cathode rays upon a number of the alkaline halices and found that they changed color but regained the original color on being heated or by the action of moist air. He ascribed the change to a physical modification and not to any chemical action taking place.

If, as Wiedemann and Schmidt suggest, the phosphorescence under cathode rays is due to the recombining of the parts of the compound which have been separated by the action of the cathode rays; then, if these parts are brought together and their combination brought about in the ordinary way, light of the same color as the phosphorescence or fluorescence should be emitted. It was for the purpose of duplicating the color of the light given out by the phosphorescence and fluorescence of these bodies that this work was undertaken.

Schluederberg $^{2}$ has shown that when an alternating current is passed through a dilute solution of sulphuric acid, using lead electrodes, a luminescence can be seen around the electrodes, becoming brighter as the solution fills up with the insoluble lead sulphate. This light must be due to the formation of lead sulphate, since with platinum or unattackable electrodes no light can be detected.

\footnotetext{
${ }^{1}$ Goldstein: Wied. Ann., 54, 37 I (1894).

2 Schluederberg: Jour. Phys. Chem., I2, 623 (1908).
} 
This experiment was repeated and tried with other metals and solutions. The solutions used were saturated potassium bromide and iodide, dilute and concentrated sulphuric acid and dilute hydrochloric acid. The metals that were tried were cadmium, zinc, lead, copper, silver, mercury and magnesium.

The electrodes were wires or thin strips of the metals about the size of a No. I6 wire, B. and S. gauge. Those were immersed in the electrolyte from two to four centimeters. In every solution the experiment was first run with platinum electrodes to see if the light was due to a state of static discharge. In no case was there any light observed with platinum electrodes. However, with the concentrated sulphuric acid the color of the light emitted was nearly always the same and from the fact that with a current of 6 amperes the voltage across the cell was from $5^{\circ}$ to 70 volts it is probable that here the light is due to a static discharge. This is the more probable from the fact that those metals which tend to become passive give the brightest light in the concentrated sulphuric acid, for example magnesium. With the dilute acids and the salt solutions the voltage never was high, being from 6 to 8 volts with 6 amperes flowing.

In all cases where the light was intense enough, it was examined with a spectroscope and found to give a continuous spectrum which would be brighter in one part. This is true of the spectra of the phosphorescence of most inorganic salts, the spectrum will be continuous but brighter in one or more parts.

In cases where the light is very faint it can be observed only after remaining in the dark for fifteen or twenty minutes so that one's eyes become sensitive.

Schluederberg used an alternating current with the lead in sulphuric acid but with all the other metals better results were obtained with the direct current, the light effect then appearing only around the anode.

The results are given in Table I: 
The Phosphorescence of Some Inorganic Salts 695

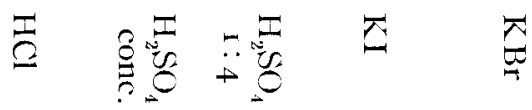

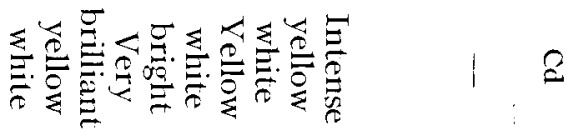

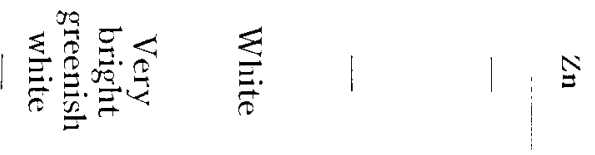

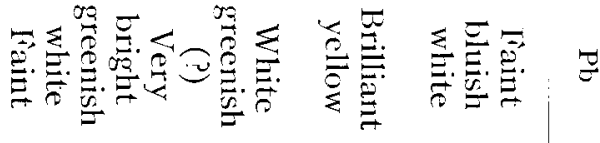

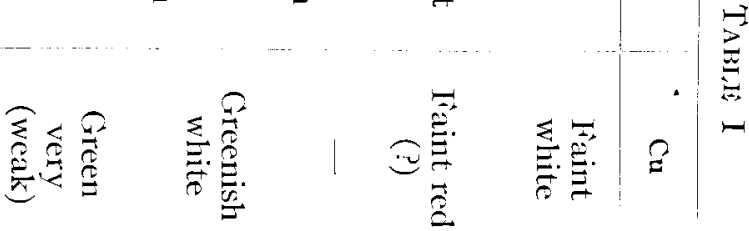

产泀 |

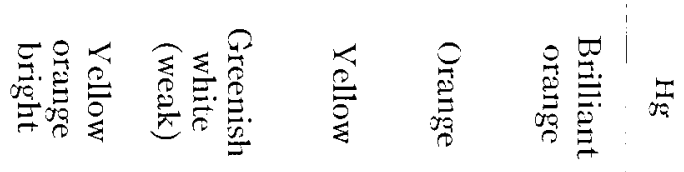

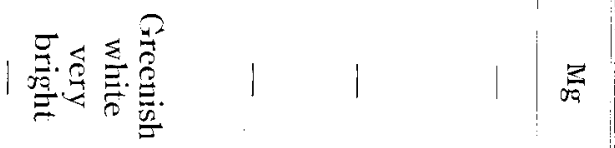


As is shown in Table I the cases where there is no light are where the salts formed are soluble, this would seem to show that one thing necessary is that the metal in corroding must form the solid salt and not remain in the dissolved state.

During electrolysis in a solution of potassium bromide cadmium electrodes give a precipitate of cadmium hydroxide, the bromide formed being soluble. In hydrochlor $\mathrm{c}$ acid no precipitate is formed and in neither of these cases is any light given out. In potassium iodide solution a film forms on the electrode and light is given out; the same thing is true with sulphuric acid.

Zinc electrodes in the bromide and iodide solutions gire a white precipitate of the zinc hydroxides, but no light is produced since the zinc salts are soluble. In hydrochloric acid no precipitate is formed and there is no light produced. In concentrated sulphuric acid there is a precipitate formed and a light effect shown.

Lead gives a precipitate in every case and gives more or less light in every case.

Copper in hydrochloric acid gives but a very thin film of cuprous chloride on the electrode and the light effect is very weak. With a copper electrode in potassium bromide the current at first seens to set free bromine and this could be seen flowing from the electrode, but this soon ceased and a vellow precipitate was formed which was dissolved by adding a few drops of hydrochloric acid to the solution. As shown in the table the light effect was weak. In potassium iodide solution the copper becomes covered with a thin film of cuprous iodide while the solution turns dark, due to iodine set free. The light effect was weak. In dilute sulphuric acid there is no precipitate and no light produced. In concentrated sulphuric acid the precipitate formed is finally divided copper and not copper sulphate.

Silver gives a precipitate in every case and also gives light in every case; and the same is true of mercury.

With mercury in a solution of potassium iodide the pre- 
cipitate is yellowish white with a circle of red next to the mercury. In potassium bromide and sulphuric acid the precipitate is greenish white. In hydrochloric acid the precipitate is a grayish black slime.

Magnesium gives no precipitate in any of the solutions and gives no light in any except the concentrated sulphuric acid.

When the salt formed is very insoluble, in order to observe the light effect it is necessary to watch carefully just at the moment the circuit is closed either by closing the switch or by holding the electrode in the hand and dipping it into the solution, after the eyes are fully accustomed to the darkness.

A special case of this is that of cadmium in potassium iodide solution. When the circuit is first closed there is no light effect for about a second, then a bright yellow luminescence is seen to travel from the bottom to the top of the anode and after that there is no more light to be noticed. This same thing is repeated each time the circuit is closed or the electrode dipped into the solution. If the process is observed in the light, on first closing the switch the electrode turns brown, growing darker and darker until the flash comes and after that it is white, being covered with a film of the iodicle. This remains until the circuit is opened and it dissolves off. It is probable that light is being given off beneath the white film but it cannot be seen. There is alwars about a second between the closing of the circuit and the appearance of the flash.

With carmiun electrodes no luminescence was obtained in potassium bromide or hydrochloric acid. With the iodide as noted above a bright yellow or yellow white was seen for an instant. Dilute sulphuric acid gives a similar bright flash. With concentrated sulphuric acid there is obtained around the anode a very bright light which gives a continuous spectrum with the direct vision spectroscope but appears yellow to the naked eye.

Zinc electrodes give positive results only with sulphuric 
acid. In dilute acid there was but little effect but as the concentration of the acid was increased the light became stronger and with concentrated acid the anode was surrounded by a bright greenish white luminescence. The solution became very hot and was filled with a white precipitate.

With lead in potassium bromide the light was bluish white but not very bright, a dense yellowish white precipitate being formed. With potassium iodide a bright yellow luminescence was obtained but it would not last very long because of the film of lead iodide clinging to the electrodes and cutting off the light. Wherever this film would break the light could be seen as a little spark. With hydrochloric acid the light effect was not very bright but was quite noticeable after the current had been running for some time, especially at the lower end of the electrode. As Schluederberg has shown, with dilute sulphuric acid and a direct current no light effect was observed because the anode became covered with a film of lead peroxide and no more lead would dissolve. With an alternating current and a $\mathrm{I}$ : io sulphuric acid solution a faint luminescence was obtained; this increased in brightness with the concentration of the acid. With very concentrated acid it becomes quite bright, being white in color. It gives a continuous spectrum with the direct vision spectroscope.

Copper electrodes in potassium iodide gave no definite light effect although with a very high current density the anode seemed to give out a very faint reddish light. With potassium bromide the light was a faint white with a tendency toward violet. The solution turns brown and a precipitate is formed. In rather concentrated hydrochloric acid only a few flashes of light were obtained and these were too faint for the color to be distinguished With dilute sulphuric acid there was no light effect but in the concentrated acid there was a flash of green just at the moment the circuit was closed. The solution fills up with fine particles of copper due to the solution of the copper as the "ous" salt and its decomposing in the solution. 
Of all the metals that were tried the best results were obtained with mercury electrodes. The mercury was held in a glass tube bent in the form of a hook, with the end broadened out like a funnel or thistle tube. Connection was made by dipping copper wires into the long arm of the tube. This gives a mercury surface of about a square centimeter for the electrode. When immersed in a solution of potassium iodide, 300 grams to the liter, and the circuit closed, a very bright orange or reddish yellow light is obtained, which lasts quite a few seconds. Besides this light there is always a circle of violet where the mercury and glass meet. This last is always neglected. With potassium bromide an orange colored light is seen, best just after the circuit is closed. With dilute sulphuric acid a bright yellow is produced. The mercurous sulphate formed cuts off the light very quickly but, by shaking this off the surface, the light will appear again. Better results were obtained by cutting the current down from 6 to 3 amperes and using a $I: 3$ solution of sulphuric acid instead of a I : Io as with the other metals. With the concentrated sulphuric acid there is less light effect and it is more greenish white in color. The film of sulphate is formed immediately. With dilute hydrochloric acid, I : Io, the mercury gives a yellowish orange light but becomes covered with a mass of black slime which cuts of the light very quickly.

Silver electrodes in potassium iodide and potassium bromide solutions give a few flashes of light but the film of the silver salt forms so quickly that it is impossible to distinguish the color. The bromide gives a light, slightly blue or violet in color. An alternating current gives no better results. Dilute sulphuric acid gives a bright white light. In hydrochloric acid the silver chloride sticks very tight and cuts off the light very quickly but if the current is allowed to flow for some time little patches of yellow light can be seen running down the anode.

Magnesium gives nothing with any solution except the concentrated sulphuric acid and, as mentioned before, this is probably due to a static discharge. When the current was 
reversed, the magnesium being made cathode and platinum anode, there was no light effect.

From these results it is seen that when these compounds, the chlorides, bromides, iodides and sulphates are formed, light is given off and on comparing the color of the light with that of the fluorescence and phosphorescence under the cathode rays as given in Table III later in the article it can be seen that in most cases there is a good agreement between them. This is especially true of the mercury salts.

\section{Experiments on Direct Chemical Combination}

The next experiments were to duplicate these light effects by chemical combination without the use of the electric current. Each metal was placed in a porcelain boat in a hard glass combustion tube and after being heated above the melting point, where this was possible, a current of chlorine, bromine or iodine vapor was passed over it and the light effect observed. The chlorine was obtained from a cylinder and was passed through water in a gas wash bottle to enable one to regulate the current and also because the alkalies do not react with dry chlorine very readily. ${ }^{1}$ The bromine and iodine vapors were obtained by placing the liquid or solid in a $100 \mathrm{cc}$ flask with a delivery tube running to the combustion tubing in which the metals were heated. When the metals were at the desired temperature the flask was immersed in hot water and the stopcock between it and the combustion tubing opened, while suction was applied to the other end thus drawing the vapors over into the tube.

On account of its striking fluorescent color under the cathode rays cuprous iodide was the first one tried. When heated in the combustion tube and iodine vapor allowed to act on it the reaction was apparently not vigorous enough to give off light.

McLean ${ }^{2}$ showed that when copper foil is heated in the air and iodoform sprinkled on it, dense fumes of iodine are

1 Merz and Holzmann: Ber. chem. Ges., Berlin, 22, 837 (1 889 ); Cowper: Jour, Chem. Soc., 43, 155 (1883).

2 Jour. Chem. Soc, 73, $153(1898)$. 
The Phosphorescence of Some Inorganic Salts 7 OI

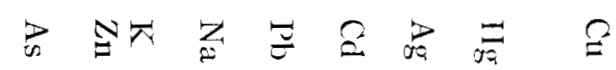

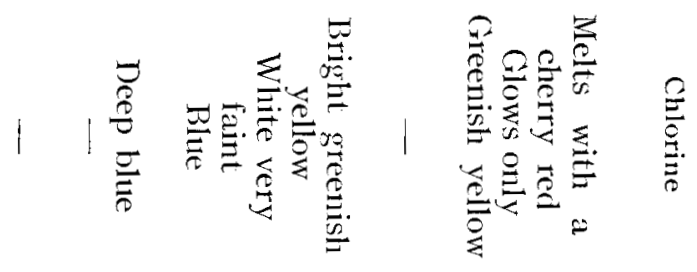

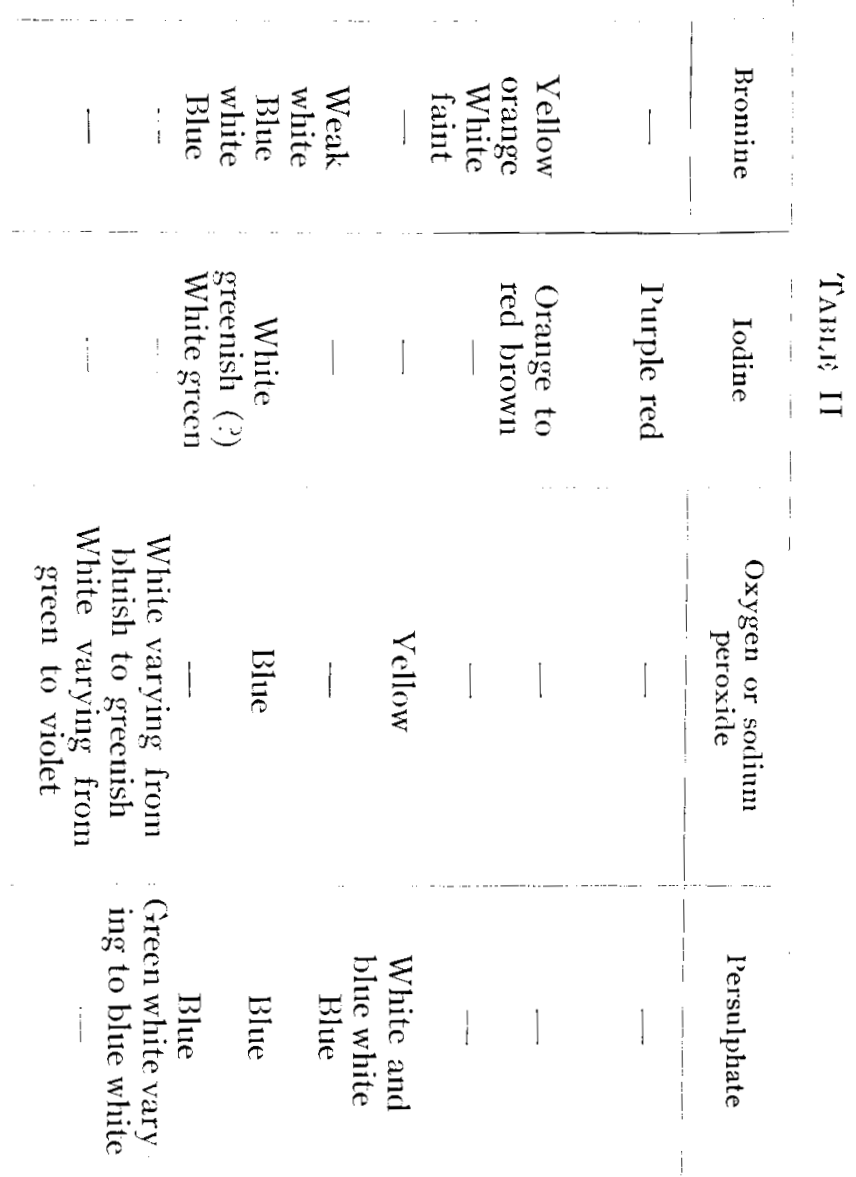


given off and a bright red flame passes over the foil. This was repeated but the flame is probably due to the oxidation of the carbon in the iodoform and not to the formation of cuprous iodide. The same experiment was tried with copper and iodine and with hydriodic acid but without obtaining any light effect. If powdered copper is used instead of copper foil it oxidizes too quickly in the air on heating. After trying many ways of bringing iodine and copper together it was found that when the copper is heated gently and a few crystals of iodine added to it, the two unite and a reddish violet light is produced, while the white cuprous iodide remains after the action.

Copper heated in a current of moist chlorine glows with a cherry red glow, but otherwise there is no light effect.

Mercury heated to boiling in a current of chlorine burns with a greenish yellow flame forming the mercuric chloride. With bromine it gives a very bright yellow orange and with iodine an orange which appears at times reddish brown as seen through the iodine vapor.

Silver gave nothing with either chlorine or iodine, but with bromine it gave a faint white. The chloride forms a film and prevents further action.

Lead gives a faint white with chlorine and bromine but nothing with iodine. With the chlorine there was always a flash of white just as the chlorine was run in and started to unite with the molten lead.

Cadmium gave a bright yellow bordering on the green with chlorine. The metal remains molten, as does the chloride formed, and floats around on top of the fused salt. The latter is somewhat red in color and the yellow color of the light due to the combination of the metal with the gas is seen above this. Cadmium gives nothing with either bromine or iodine.

When trying some experiments upon the decomposition of mercuric chloride with metallic sodium which will be described later, a bluish white luminescence was obtained; but 
on tracing this down it was found to be due to the slow oxidation of the metallic sodium.

Wiedemann and Schmidt ${ }^{1}$ showed that the thermoluminescence or phosphorescence of sodium chloride was blue and if this is due, as we think, to the recombination of the chlorine and sodium which have been set free by the cathode rays then the combination of these should give a blue light. As was seen with sodium and the oxygen in the air the slow union did give that color and therefore the same thing was to be expected with chlorine.

When a slow current of chlorine is passed over metallic sodium, in the form of a fine wire, placed in the combustion tubing at ordinary temperatures the sodium gives quite a bright light-blue luminescence and the brightness increases with the strength of the chlorine current until the sodium bursts into flame with the usual color. If allowed to react slowly the metal becomes covered with a layer of the chloride and the luminescence will cease.

To show that the blue light was not due to the oxygen of the air the tube was first swept out with dry hydiogen and then chlorine was run in. As soon as the chlorine came in contact with the metal the light was seen. The current of chlorine was increased until the sodium burst into flame and this set off the mixture of hydrogen and chlorine and a slight explosion resulted. This shows that the blue light can be caused by chlorine as well as by oxygen. The same thing was tried with bromine and iodine; the former gives a bluish white light, weaker than with chlorine, while the latter gives a white light with a trace of green.

Potassium treated in the same way reacts much more violently with chlorine than sodium does and therefore it is harder to get the slow combustion to show as well. However, at the end of the piece of potassium towards the cylinder there was always a deep blue light, very different from the characteristic violet of potassium. The heat of the reaction is so great that in nearly every experiment the glass tubing

1 Wied. Ann., 56, 203 (1895). 
was broken. The residue left behind after the action was always colored greenish blue, but if allowed to stand in the open air for twenty-four hours it would lose all the blue color and become yellowish white. This blue is caused by the excess of potassium remaining unacted upon; by the action of the moisture in the air this is converted over into the hydroxide and thus destroys the color. With bromine, potassium gave a bluish green light, which was stronger than bromine with sodium but weaker than the potassium with chlorine. With iodine the potassium gave a faint white, colored slightly green. This could best be seen by placing some crystals of iodine upon a piece of potassium in a porcelain boat and warming gently.

\section{Light Due to Formation of 0xides}

This was brought out in two ways, either by burning the metal in a stream of oxygen or by addling sodium peroxide to the molten metal.

Bisnuth, tin, zinc and carlmium all give negative results when heated in a current of oxygen. However, when cadmium is heated with a blast lamp until it volatilizes, it combines with oxygen and burns with a deep yellow flame to the reddish brown oxide. Zinc heated in the blast to boiling burns with a green flame.

Arsenic gives peculiar results in that the color of the flame depends entirely upon the rate at which the oxygen is run into the tube. When pure oxygen is used, the color of the flame is a bluish white with now and then a flash of green for a moment. When air is used the color tends more towards the yellow green. If the air or oxygen supply is cut down very low so that the arsenic just barely burns, the color of the flame is green, and by increasing the supply one can vary the color from a green up to the blue.

When sodium is oxidized with a very slow current of oxygen the luminescence is blue and the sodium is converted into a white powder, but when the oxidation is done rapidly the sodium burns with the characteristic yellow flame and leaves a yellowish white residue of the peroxide. 
If a piece of sodium is placed on water, a trail of bluish white light follows it; as it rolls around over the surface the color is similar to that when sodium is oxidized slowly. Apparently then in all these cases where sodium reacts slowly the color of the luminescence is blue; at least this has been shown in the case of its action on chlorine, bromine, iodine, oxygen and water.

\section{Experiments with Sodium Peroxide}

Molten lead treated with sodium peroxide reacts very violently, the heat of the reaction being sufficient to fuse the whole mass, which becomes cherry-red, but otherwise there is no luminescence visible.

Cadmium in the same way is changed to the brown oxide and the mass during the reaction resembles burning soot.

Copper powder oxidizes too easily in the air on heating to show any luminescence.

When molten zinc is treated with a large amount of sodium peroxide it reacts violently, blows out of the crucible, and nearly every time breaks the bottom out of the crucible. When the peroxide was added a little at a time to the molten metal, there was a popping and splattering; but the flame was visible and varied from a blue to a green with a tendency towards the green.

\section{Experiments with Ammonium Persulphate}

On the basis that the fluorescence and phosphorescence of the sulphates is due to the recombination of the metal with the $\mathrm{SO}_{4}$ radical after being separated by the cathode rays, an attempt was made to duplicate this by the action of the molten metal upon ammonium persulphate, which will break down into ammonium sulphate and the sulphate group $\mathrm{SO}_{i}$. The latter, on being set free, will react with the metal.

Molten lead treated with the perstilphate gives a bluish white light just as the mass is solidifying. This can best be seen by stirring the mass with a glass rod and as it solidifies a bluish white streak of light will follow the rod. 
Cadmium in the same way gives a white streak and zinc gives a greenish white.

After the violence of the reaction on first adding the persulphate, sodium and potassium give a blue or blue-green luminescence. Mercury gives no light effect. When calcium is heated to a bright red heat before adding the persulphate, it gives a flash of white just at the moment the persulphate is added and before a film of the calcium sulphate is formed. The light ceases almost immediately.

Since the ammonium persulphate breaks down so readily and gives off dense fumes which obscure the light effect, the potassium salt was tried instead. This deepens the blue of the lead when added to the white hot metal, gives a greenish blue with cadmium and a blue with zinc.

Apparently there is a new factor that has entered into the question and that is the light due to the decomposition of the potassium persulphate or, viewed from the other side, the formation of the potassium sulphate from the persulphate. As was seen, the action of ammonium persulphate on metallic potassium gave a blue luminescence, so the formation of potassium sulphate is accompanied by a blue light effect. Potassium persulphate was added to hot powdered charcoal and the same blue was obtained although weaker than when the metals were present. This shows that the decomposition of the persulphate or the formation of the sulphate gives a blue light.

Next, some persulphuric acid was prepared by treating a saturated solution of the ammonium salt with concentrated sulphuric acid while the solution was kept cold in a freezing mixture. Some of the clear solution was pipetted off and added to molten lead, cadmium and zinc when results similar to those with ammonium persulphate were obtained. Next, concentrated sulphuric acid was added to the molten metals and all gave a faint blue.

The peculiar point about the light is that it does not come from all over the surface of the hot metal but from along the sides of the crucible and where there are holes in the sur- 
face of the persulphate crust. Apparently the light comes from below and is reflected upon the vapors of the decomposing sulphate.

These experiments seem to show that the sulphates have their own color of luminescence due to their formation, but that this is often masked by the light due to the decomposition of the persulphate.

\section{Experiments with Solid Sulphur Trioxide}

As it is possible that the cathode rays might cause a sulphate to decompose into the oxide and sulphur trioxide, instead of into the metal and the sulphate group, and since the light would then be due to the recombining of these, some experiments were made on the action of solid sulphur trioxide on heated metallic oxides.

Cadmium oxide gives a bright yellow light, zinc oxide a bright green, lead oxide a white, while calcium, barium and strontium oxides all give a bright yellowish white light which is not characteristic.

\section{Experiments with Hydrofluoric Acid}

When metallic sodium is added to hydrofluoric acid in a platinum dish, it floats around over the top just as it does on water. By close observation a faint bluish white light could be seen following the metal globule. The light was probably due to the water in the acid as the light was of the same color, but less intense then when sodium acts upon water.

Potassium reacts much more violently, the globule of metal exploding almost as soon as it strikes the liquid. Calcium and magnesium gave no light effect.

These experiments with hydrofluoric acid are hardly to be considered as similar to the preceding ones or to those that take place during fluorescence and phosphorescence under the cathode rays, because they are metathetical reactions and not a direct union of the elements.

Another similar experiment which is open to the same objection was tried. A saturated solution of lead acetate 
was added to a saturated solution of sodium sulphate in the dark, both solutions having first been heated to boiling. No light effect was observed during the formation of the precipitate of lead sulphate. The same thing was tried with lead acetate and concentrated sulphuric acid but with negative results; also with mercurous nitrate and potassium chloride.

A saturated solution of cadmium sulphate was treated with concentrated sulphuric acid to see if there would be any light given out during the crystallization of cadmium sulphate from the solution. This also gave negative results.

These experiments show that, at least in water solutions, these metathetical reactions will not produce any luminescence.

\section{Experiments on the Decomposition of Phosphorescent Salts}

Up to this time the experiments have been dealing with the light given out by the combining of the elements or the metal with the acid radical, and it has been shown that in many cases there is a coincidence between the color of the light given by the chemical action and that of the fluorescence or phosphorescence under the cathode rays. The question may be asked whether the light might not be due also to the decomposition of the compounds also. An attempt was made to decompose the phosphorescent salts with metallic sodium both by heating them and by grinding them together in a mortar.

Lead sulphate, lead oxide, zinc oxide, mercurous and mercuric chlorides and cuprous iodide were treated in this way but no light effect was noticed except the bluish white due to the slow oxidation of the sodium in the air or possibly the combination of the sodium with the chlorine, iodine or sulphate group. The mercurous and mercuric chlorides turned black and yellow respectively showing that decomposition had taken place but in no case was any light observed except that due to the sodium.

The same result was obtained by adding molten sodium 
to hot mercuric chloride, no light except that due to the sodium being observed.

\section{Electrolysis of Fused Salts}

P. Lenard ${ }^{1}$ has shown that the molten salts of the alkali metals have a glow which varies with the metals and is independent of the acid radical present.

Lithium glows with a blue color, sodium blue, potassium green and rubidium and caesium with a yellow green.

As will be seen these colors agree with the phosphorescent colors of the alkali metals and it was thought that this light might be due to the formation of different salts by a reaction between the parts similar to what takes place in phosphorescence.

By electrolyzing the molten salt with an alternating current it was thought that possibly the two being set free at the same electrode might unite and give out this light. Although several of the salts were tried only negative results were obtained.

Lenard accounts for the color as due to the free metal atom and says each metal has its own particular color.

\section{Theoretical}

There are four possible explanations for the phenomena of phosphorescence and fluorescence under cathode rays as due to chemical action. ${ }^{2}$

I. The decomposition of the compound gives out light.

II. The recombination of the dissociated parts gives out light.

III. Both decomposition and recombination give out light.

IV. The change to allotropic forms gives out light.

If the first of these is the explanation, and the light is due to decomposition brought about by the exciting agents, either cathode rays, sunlight, spark discharge or anything

1 Drude's Ann., I7, I99 (1905).

2 Tiedemann and Schmidt: Wied. Ann., 56, 243 (r895). 
else, it will be visible only during the time of excitation. Therefore there can be no phosphorescence or thermophosphorescence.

If the second is the explanation there can be all three and the light given out will always be the same color. As soon as the excitation starts, some of the compound will be decomposed and the parts will tend to reunite and give out light. Finally, a state of equilibrium will be reached between the decomposition and recombination. When the excitation is stopped the recombination will continue and give phosphorescence. If the temperature is raised, the velocity of the reaction of recombination will be increased. and we shall have thermoluminescence, the fluorescent, phosphorescent and thermophosphorescent lights, all being of the same color because they are all due to the same reaction.

If, as in the third class, both the decomposition and recombination produce light, these may be of the same color or they may be of entirely different colors. If of the same color, then the fluorescence, phosphorescence and thermophosphorescence will have the same color and it would be hard or impossible to distinguish between this case and that where recombination alone gave the light. However, if the decomposition gives a different light from the recombination then there will be a difference between the color of the fluorescence and the phosphorescence. The fluorescence is the color of the decomposition modified by the recombination that takes place during the excitation. The phosphorescence will have the color due to recombining alone. At all times the thermoluminescence will be the same as the phosphorescence since it is due merely to an increased velocity of the recombination.

In all cases of phosphorescence the duration of the light will depend upon the velocity of the recombination and it is possible that this velocity may be so great that there will be no phosphorescence even if the light is due to a recombination. 
There is always a possibility that instead of it being the decomposition or the reformation of the original body that gives the light, the fluorescence and phosphorescence may be due to the formation or decomposition or a third body which is formed by the exciting agent. To simplify this it can be put in the form of symbols, where $A$ stands for the original substance, $\mathrm{B}$ the decomposition products under the cathode rays, $\mathrm{C}$ is the second decomposition product formed by the action of the cathode rays upon $B$.

I. $A \rightarrow B$ gives out light.

II. $A \longleftarrow B$ gives out light.

III. A $\rightleftarrows B$ both give ont light.

IV. $\mathrm{A} \longleftrightarrow \mathrm{B} \longrightarrow \mathrm{C}$; change from $\mathrm{B}$ to $\mathrm{C}$ gives out light.

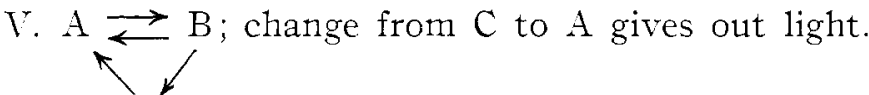

$\mathrm{C}$

If the light is due to allotropic changes the above reasoning will hold just as for chemical action. An equilibrium will be reached between $A \rightleftarrows B \rightleftarrows C$ and the fluorescence and phosphorescence will depend upon which one of the transformations gives out light.

Consider these groups separately. There is no example which can definitely be placed under the first group. The case of aluminum oxide studied by Wien ${ }^{1}$ which will be discussed later would seem to come under this group, but after examination it is found that it does not.

Under the second group, where it is simple combination that causes the light, can be placed those cases where both phosphorescence and fluorescence are of the same color and the same as the thermoluminescence. However, as mentioned before, it is not necessary that there shall be all three as the velocity of combination may be so great that the last two will be unnoticeable. In this group can be placed the larger part of the phosphorescent inorganic bodies as can be seen in Table III which is given later.

1 Wien: Phys. Zeit., 3, 440 (I902). 
In the third class or group where both decomposition and recombination give out light we can place definitely those salts which have a different fluorescent color from a phosphorescent. Besides these probably there are some of the cases where the light is the same color that fall into this group but they cannot be distinguished at present. The chief members of this group are the alkaline halides. As can be seen in Table III in nearly all cases the fluorescence is different from the phosphorescence. By a comparison of the colors with those given of by the direct combination shown in the beginning of the paper it is seen that it is the phosphorescent light that agrees, therefore it agrees with our theory that the phosphorescent light is due to the recombination. Take the case of sodium chloride for example.

Fluorescence under cathode rays whitish, slightly blue. Phosphorescence weak.

Thermophosphorescence bright blue.

Under the fourth group where the light is due to the reaction between a second decomposition product of the cathode rays, there is one example known, that of sodium peroxide. The cathode rays decompose the peroxide into the oxide and oxygen, and this reaction is not accompanied by light. Then the cathode rays decompose this oxide into sodium and oxygen and the recombination of $\mathrm{Na}$ and oxygen give the light.

At present there are no examples of the fifth group known, but probably when the problem of phosphorescence is studied along this line some examples will be found.

In Group VI may be placed calcium sulphicle whose phosphorescence has been shown to be due to allotropic transformations. ${ }^{1}$

\section{Phosphorescence of Aluminum Oxide}

Wien $^{2}$ has shown that aluminum oxide prepared by precipitation and dehydration of the hydroxide is not fluor-

Waentig: Zeit. phys. Chem., 5I, 4/ I (1905).

2 Wien: Phys. Zeit., 3, 440 (1902). 
escent or phosphorescent under the cathode rays, while that which is prepared by burning the aluminum powder in the air or in oxygen is fluorescent and phosphorescent under the cathode rays and gives off oxygen during the action of the cathode rays. This might seem to be an example of the first group where the light is due to the decomposition of the substance, but since it shows phosphorescence after the exciting agent has ceased, the light cannot be due entirely to the decomposition.

Since the ordinary aluminum oxide does not show this fluorescence, while that formed by burning the metal in air does, there must be sone difference between the two and this can be due either to the metal burning to some other compound, say a peroxide, or to the metal having impurities present in it which cause the fluorescence after burning in air.

Some aluminum peroxide was prepared by the method of Gibson and Morrison ${ }^{1}$ by precipitating the peroxide with an alkali and adding an excess of the latter to just dissolve the precipitate, then adding hydrogen peroxide, filtering off the precipitate formed and drying at $I 10^{\circ} \mathrm{C}$. This material showed no light effect under the cathode rays, and so the peroxide theory is eliminated.

Owing to the method of preparation of metallic aluminum by the electrolysis of bauxite in a fused bath of cryolite the natural impurity present would be sodium. If this were present it would burn in the air to sodium peroxide and this under the action of the cathode rays might give off oxygen due to its decomposition.

Some sodium peroxide was exposed to the action of the cathode rays for an hour. At first there was no light effect, but by keeping the pump going all the time and thus keeping a high vacuum the oxide became fluorescent and showed phosphorescence of very short duration. The color of the light was a yellowish white, the same as that shown by the aluminum oxide. The only difference was in the duration of the phosphorescence, that from the sodium peroxide last-

\footnotetext{
${ }^{1}$ Proc, Roy. Soc., Edin., II9, I46.
} 
ing but a fraction of a second while the aluminum oxide remained bright for several minutes. The sodium peroxide gradually turned white on the surface, due probably to the formation of sodium oxide and the liberation of oxygen. After an exposure of more than an hour the surface had turned slightly brown, due to metallic sodium from the deconiposition of the oxide.

Sodium peroxide was added to aluminum oxide which had been prepared by the usual precipitation method and showed no fluorescence under the cathode rays. These were ground together and then heated until the mass just caked. On exposure to the cathode rays after cooling, the fluorescence and phosphorescence was of the same color and intensity as that of the aluminum oxide prepared by burning in air, the only difference being the duration of the phosphorescence.

The surface of the material was a deep blue color after an exposure of half an hour to the cathode rays. On the addition of water to this blue it turned white and gave off bubbles of gas. This blue is probably the metallic sodium dissolved in the mixture of the two oxides.

On the supposition that the sodium peroxide united with the aluminum oxide to form sodium aluminate, some sodium aluminate was prepared by dissolving the aluminum hydroxide in an excess of sodium hydroxide and evaporating to dryness. This showed fluorescence but the residue was not colored blue by the cathode rays even after an exp.sure of over an hour. This material differed from the mixture of the two oxides that did turn blue, by having an excess of alkali instead of an excess of alumina, so some sodium hydroxide was added to an excess of aluminum hydroxide and the mixture evaporated to dryness and ignited over a blast lamp. This on exposure to the cathode rays gave a deep blue residue and showed the same fluorescence as before. Besides this there were some spots where the mixture had a blue fluorescence.

The excess of alkali in the first aluminate prevented 
the formation of the blue either because the water was not all out of the mixture, being retained by the alkali; or because it prevented the sodium from dissolving in the aluminate when it was set free by the cathode rays.

These results seem to show that the fluorescence and phosphorescence of aluminum oxide, prepared by burning the metal in air, is due to the presence of sodium in the aluminum; when the alloy burns the sodium is converted into the peroxide.

Pure alumina shows no fluorescence or phosphorescence under the cathode rays. Sodium peroxide shows fluorescence and phosphorescence under the cathode rays in a high vacuum after a long exposure. This is due to the reaction between the sodium and oxygen which are the products of the second stage in the decomposition of the sodium peroxide, which takes place in the following steps:

$$
\mathrm{Na}_{2} \mathrm{O}_{2}=\mathrm{Na}_{2} \mathrm{O}+\mathrm{O}=2 \mathrm{Na}+\mathrm{O}_{2} \text {. }
$$

There is apparently no light given out by the decomposition of the peroxide in the first stage but the light is due either to the decomposition of the $\mathrm{Na}_{2} \mathrm{O}$ or to its reformation after being decomposed by the cathode rays. The residue after the action of the cathode rays was brown, due to the metallic sodium set free.

Sodium aluminate showed fluorescence and phosphorescence under the cathode rays, the same color as that of aluminum oxide prepared by burning the metal in air. Beside this yellow white light it also showed spots of blue fluorescence.

The residue after the action of the cathode rays was colored a deep blue, due to a solution of the sodium in the aluminate. The same results were obtained by mixing the sodium peroxide with an excess of aluminum oxide. However, when the aluminate is prepared with an excess of alkali present, this prevents the sodium from being set free and dissolving in the aluminate and hence the residue does not turn blue.

We may consider then the sodium present in the aluminum oxide prepared by burning the metal in air to be there in the 
form of peroxide. This will account for the liberation of oxygen and the fluorescence and phosphorescence.

If the sodium peroxide unites with the aluminum to form the aluminate and is present in that form the light given out would be due to the decomposition or reformation of the aluminate.

Whether it is there as the peroxide or the aluminate could no doubt be decided by the rate at which oxygen is liberated by the action of the cathode rays since it would be more rapid in the decomposition of the peroxide than the aluminate. No experiments were made to ascertain this point.

\section{Phosphorescence of Alkaline Halides}

Wiedemann and Schmidt account for the color changes that take place in the halides of the alkali metals by assuming the formation of a sub-salt of the formula $\mathrm{X}_{2} \mathrm{Cl}$, or of the setting free of the free metal. They assume the formation of the sub-salt for the following reasons:

(I) The substance formed by the action of the cathode rays reacts alkaline to litmus or phenolphthaleine.

(2) The halogen is given off during the exposure.

(3) Sub-salts prepared by the electrolysis of the molten salt have the same properties as the substance formed by action of the cathode rays. They react alkaline, have the same color, show thermo- and lyo-luminescence, lose their color and become white on heating or by action of moist air.

They account for the alkalinity of the sub-salt by this reaction:

$$
\mathrm{Na}_{2} \mathrm{Cl}+\mathrm{H}_{2} \mathrm{O}=\mathrm{NaOH}+\mathrm{NaCl}+\mathrm{H} .
$$

Kirchhoff and Bunsen ${ }^{1}$ and Rose ${ }^{2}$ were the first to describe these sub-salts of the alkalies. R. Lorenz in his "Elektrolyse geschmolzener Salze" has shown that during the electrolysis of fused salts there is formed what he terms a "metal fog," of the particles of metal suspended in the molten salt. It is really a colloidal suspension of the metal in the melt.

\footnotetext{
1 Pogg. Ann., II3, 345 (I86I).

2 Ibid., I 20, I ( 1863 ).
} 
Zsigmondy in "Zur Erkenntnis der Kolloide," page 58, has shown that when the blue form of sodium chloride is examined with the ultramicroscope fine particles of the metal can be seen.

From this it is apparent that instead of the color of the substances formed by action of the cathode rays or by electrolysis of the fused salt being due to a sub-salt, they are probably due to the finely divided metal. As mentioned before, when a piece of sodium is dropped on water it gives off a faint or pale blue light as it floats over the surface, due to its action on the water. This will account for the luminescence or phosphorescence when the so-called sub-salt goes into solution.

When metallic sodium is rubbed in a mortar it reacts with oxygen and gives a pale blue light. This will account for the frictional phosphorescence of the sub-salt.

Since the method of preparing the sub-salts by electrolyzing the fused salts was ideal for obtaining this metal fog through the mass, it is to be expected that they would show the reactions for the metals.

In the case of the halogen salts, there is practically no question as to what the reacting bodies are that give the light. It is either the reaction of the halogen upon the metal or possibly upon the subchloride. In the case of the alkalies the former reactions have been shown to be the more probable. However, when we consider the case of the sulphates the question is not so simple, as the reaction may be between:

(I) Metal and $\mathrm{SO}_{4}$.

(2) Metal and oxygen.

(3) Oxide and sulphur trioxide.

Take the three sulphates that were studied, cadmium, lead and zinc, and consider the data to see which of these explain the phenomena.

Cadmium Sulphate.

$\mathrm{Cd} \div \mathrm{O}=$ gives a bright yellow light.

$\mathrm{CdO} \div \mathrm{SO}_{3}=$ gives a bright yellow.

$\mathrm{Cd}+\left(\mathrm{NH}_{4}\right)_{2} \mathrm{~S}_{2} \mathrm{O}_{8}$ gives white (weak). 
$\mathrm{Cd}+\mathrm{H}_{2} \mathrm{SO}_{4}$ in electrolysis yellowish white.

$\mathrm{CdO}+\left(\mathrm{NH}_{4}\right)_{2} \mathrm{~S}_{2} \mathrm{O}_{8}=$ nothing.

Fluorescence and phosphorescence in cathode rays gives a bright yellow.

It would seem in this case that the light must be due either to the formation of the oxide or to the action between the oxide and sulphur trioxide. When sulphuric acid is electrolyzed between cadrinium electrodes the anode first becomes covered with a brown film of the oxide and the formation of this does not give out light. This turns white and in doing so a flash of light is seen. One would therefore say that the light does not come from the formation of the oxide. Hence it must come from the action of sulphur trioxide upon the oxide. That this is the reaction is also shown by the fact that when cadmium sulphate is exposed to strong and prolonged cathode rays it becomes covered on the surface with a yellow powder which resembles the oxide.

Zinc Sulphate.

Zinc $+\mathrm{O}=$ gives a bright green.

$\mathrm{Zn}+\mathrm{Na}_{2} \mathrm{O}_{2}=$ bright greenish white.

$\mathrm{Zn}+\left(\mathrm{NH}_{4}\right)_{2} \mathrm{~S}_{2} \mathrm{O}_{\mathrm{s}}=$ bluish white.

$\mathrm{Zn}+\mathrm{H}_{2} \mathrm{SO}_{4}$ in electrolysis gives greenish white.

$\mathrm{ZnO}+\mathrm{SO}_{3}=$ very bright green.

Zinc sulphate in cathode rays fluoresces bluish white or Wiedemann and Schmidt call it white.

From the above it can be seen that the phosphorescence of zinc sulphate cannot be due to the action of $\mathrm{SO}_{3}$ on the oxide and must be due to the action of $\mathrm{SO}_{4}$ on the metal.

Iread Sulphate.

$\mathrm{Pb}+\mathrm{O}=$ gave no light effect.

$\mathrm{Pb}+\mathrm{Na}_{2} \mathrm{O}_{2}=$ gave nothing definite.

$\mathrm{PbO}+\mathrm{SO}_{3}=$ white.

$\mathrm{Pb}+\left(\mathrm{NH}_{4}\right)_{2} \mathrm{~S}_{2} \mathrm{O}_{8}=$ blue.

$\mathrm{Pb}+\mathrm{H}_{2} \mathrm{SO}_{4}$ by electrolysis apparently white but too faint to judge well.

$\mathrm{PbO}$ has a white fluorescence in cathode rays.

$\mathrm{PbSO}_{4}$ has a bright blue fluorescence in cathode rays. 
Here, as in the case of zinc sulphate, the fluorescence cannot be due to the action of the sulphur trioxide upon the oxide as this gives white.

Since the formation of the lead sulphate by the action of the persulphates gives a blue light this must be the reaction that takes place during the fluorescence, namely the union of the lead and the $\mathrm{SO}_{4}$ ion.

Further, the action of a heavy and continued discharge of cathode rays upon lead sulphate leaves the surface covered with a black or grayish black powder which is insoluble in sodium acetate and hence cannot be the oxide and must be the finely divided metal.

On repeating the observations of Wiedemann and Schmidt on the phosphorescence of the inorganic sa'ts in the cathode rays there was a good agreement with their results in nearly all cases but in a few instances the compounds failed to show any fluorescence, zinc oxide and sulphate and lead oxide being the chief ones. The cadmium sulphate that was first tried was a sample from DeHaën and showed a very brilliant fluorescence and phosphorescence. A sample from Baker and Adamson was much fainter and one from Kahlbaum which was marked 99.99 percent pure did not show any light at all.

On microchemical analysis the material from DeHaën showed quite a strong test for sodium, a less one for zinc and a very faint coloration with $\mathrm{KCNS}$ and $\mathrm{K}_{4} \mathrm{Fe}(\mathrm{CN})_{6}$ for iron, after removing the cadmium with hydrogen sulphide, concentrating the filtrate, precipitating with ammonium sulphide and testing the greenish black precipitate for zinc and iron.

On the supposition that the fluorescence is due to one or more of these as an impurity, they were added in small amounts to the pure cadmium sulphate to see if they would then produce phosphorescence. The addition of about $\mathrm{O}$. I percent of sodium sulphate made the cadmium sulphate phosphoresce very brightly, nearly as much as the DeHaën material. Addition of zinc sulphate in similar amount made it active but not as much as the sodium. Potassium and 
lithium sulphates were tried and they both caused the same light and to about equal degree. Copper and bismuth present in snall amounts have no effect, that is, the cadmium sulphate does not phosphoresce.

It has been shown in the case of the phosphorescence of calcium sulphide that the addition of copper, manganese or bismuth cause it to phosphoresce, each with a different color. In the case of cadmium sulphate all the impurities cause the same color. Here then the light is due to the energy of the union of the dissociation products being changed into light by the agency of the impurities, the color being that of the cadmium sulphate. With the calcium sulphide the light is apparently not due to the specific action of the calcium sulphide but is dependent upon the metal impurity that is present, each giving its particular color.

It was observed that the cadmium sulphate which did not show any phosphorescence, the pure material, when exposed to the cathode rays for a long time showed signs of decomposition upon the surface even though it was not active. This indicates two things, first the phosphorescence in cathode rays is not due to decomposition and second that the other metal must be present to cause the energy of the recombination to appear in the form of light. Otherwise, it is set free in some other form, probably heat.

To show how small an amount of an impurity will cause a salt to be phosphorescent there is an interesting case with pure cadmium sulphate. If the dry salt is heated over a Bunsen burner to drive out the water of crystallization the resulting powder is not phosphorescent, but when the salt was dissolved in water which had been twice distilled, the second time from sulphuric acid solution, and this solution was evaporated to dryness in the same way as before, the resulting powder was brilliantly phosphorescent. Plainly there was still something in the water that had this effect. Two hundred cubic centimeters of this water were evaporated in a large platinum dish and the residue left was so small that it could be seen only when the platinum dish was red- 
hot. This amount of solid had been dissolved from the bottle in which it had stood over night. It was, however, sufficient to cause the cadmium sulphate to phosphoresce very brightly.

Some of the zinc of the sulphate which showed no phos. phorescence in the cathode rays was dissolved in water and a very small amount of sodium sulphate was added evaporated to dryness and ignited over a Bunsen burner until all water was driven off. This showed a bluish white phosphorescence of very short duration. Copper and bismuth present in small amounts cause the same phosphorescence as the sodium. Cadmium sulphate was added in the same way. The first addition caused a very faint bluish white phosphorescence. On increasing the amount of cadmium the light increased in intensity all the time and remained the same color. However, after adding about I percent of cadmium sulphate the light became white and tended more towards the yellow although it was still of short duration and not long like the cadmium sulphate. When equal parts of the two were mixed and evaporated down together in this way the resulting phosphorescence is bright yellow like the cadmium sulphate.

A very small amount of manganese added to zine sulphate made it phosphorescent with a bright reddish yellow color.

That the halogen is given off from the halide salts of some of the heavy metals when exposed to the cathode rays has been shown conclusively by an experiment of Goldstein ${ }^{1}$ who placed a piece of copper near some silver iodide exposed to the cathode rays. At first the copper was not fluorescent but some of the iodine given off by the silver iodide united with the copper and formed the cuprous iodide which then fluoresced with its characteristic red-violet color.

This experiment was repeated using copper powder instead of the foil. At first the powder did not give out light, then it became very bright and finally died away again, the surface becoming grayish brown, due to the decomposition of the copper iodide.

${ }^{1}$ Jour. Phys. Chem., I3, 54 (rgog). 
That there is chemical decomposition by the action of the cathode rays is shown also by the salt turning dark and leaving a colored residue. All of the first group of Wiedemann and Schmidt's classification show this very strongly and it is difficult to draw the line between the first and second group because some of the latter show evidence of decomposition on long exposure. This is the same with cadmium sulphate. When exposed to a heavy discharge for a long time the surface becomes covered with a yellow-brown powder, especially at the edges of the crystals which project up from the surface. In the same way lead sulphate becomes gray on the surface.

That this is not a deposit of particles from the electrode or of organic matter was shown in two ways.

Lead and cadmium sulphates were placed side by side and exposed to the cathode rays at the same time. The former was acted upon more strongly than the latter and the residue was gray while with the latter it was yellow brown. This shows that the lead sulphate is more easily decomposed and that the residue is from the salt and not from the electrode.

This was shown in the second way by placing a sheet of lead with a hole in it over the salt during the exposure. The salt turned brown only where the rays struck the surface. If the coating had been due to organic matter or to particles from the electrode they would have been deposited upon the lead or around the circumference of the salt where the rays struck it and not in the direct path of the rays.

The gray residue from the lead sulphate was insoluble in ammonium acetate so it could not be the oxide but must be the finely divided metal. With the cadmium the residue is the oxide.

In Table III will be found the results of this work, showing the relation between the color of the fluorescence, phosphorescence and thermo-phosphorescence and the color of the light given out when the salt is formed by electrolysis and direct combination. 
In Table III we see the close agreement between the color of the fluorescence and the light given out by chemical union.

With sodium chloride the light given out during chemical combination is the same as that of the thermo-phosphorescence. Since the sodium cannot be used as an electrode there is no result under electrolysis.

The same thing is true with potassium chloride.

The color of the fluorescence of mercurous chloride is the same as the light given out during electrolysis, while that of mercuric chloride is the same as the light given by the burning of mercury in chlorine. This is just as is to be expected since by electrolysis one obtains chiefly the mercurous salt while by d rect union the mercuric salt is formed.

There is an apparent disagreement in the case of silver chloride but in both chemical combination and electrolysis the light was very weak and so it was hard to distinguish the color and for this reason one cannot say with certainty that there is a disagreement.

The same thing is true in regard to copper chloride, the non-agreement may be due to the faintness of the light during electrolysis. This is true also with lead chloride.

Sodium bromide shows agreement between the color of the fluorescence and that of the light given out by direct combination.

Potassium bromide apparently does not show agreement but the reason for this is that the light given out by direct union is a blue green and it is hard to distinguish the exact color.

- Silver bromide shows more or less agreement. During electrolysis the film forms so quickly and clings so tightly that there is but a short flash of light at the moment the current is turned on. In causing the direct union of the elements the silver must be heated to a red heat before the union will take place fast enough to give out light. Therefore the faint light due to this chemical combination is hard to distinguish against the bright background of the heated metal. 
Mercurous bromide like the chloride agrees with the light given out during electrolysis while the mercuric bromide agrees with the light of direct union.

This again is as it should be since it is the mercurous salt that is formed during electrolysis and the mercuric salt during direct union of the elements.

Cadmium bromide gives no light effect either during electrolysis or direct combination. As mentioned before this may be due to the fact that during electrolysis the solid cadmium bromide is not formed but remains in solution.

Sodium iodide gives white light both during phosphorescence and direct chemical combination.

Potassium iodide shows fairly good agreement, the fluorescent light being green while the light given by direct union is greenish white or light green.

The iodides of mercury do not show very good agreement and this is because of the fact that when iodine and mercury are heated together it will depend upon which element is in excess, whether the mercurous or mercuric salt is formed. If the salt that is formed is treated with water or alcohol, part of it will dissolve and part will not, showing that a mixture of the two is present. Since at the surface of the boiling mercury this element will be in excess it will be the mercurous iodide that will be formed and hence the light given out will be that due to the formation of the mercurous salt. This is apparently what happens. Silver during direct combination with iodine gave no light and during electrolysis in a solution of potassium iodide the light is too faint to enable one to distinguish the color.

Lead iodide does not show agreement as the fluorescence is green while the light obtained during electrolysis is yellow. However, this yellow is toward the green portion of the spectrum and not towards the red.

Cuprous iodide shows very good agreement; the fluorescence, the light from direct union and the little light that is given out during electrolysis are all of the same color. 
Cadmium iodide gives the same color during electrolysis as the fluorescence, but direct combination gave no light.

Potassium sulphate gives the same color in fluorescence as in direct combination, the only difference being the depth of the color.

Magnesium sulphate does not agree and the reason as given before is that during electrolysis in concentrated sulphuric acid the light given out is due to a static discharge and not to the formation of magnesium sulphate. No light was obtained by a direct union of magnesium and the sulphate group.

The fluorescence of lead sulphate is the same color as the light from the union of lead with the sulphate group. The light given out by the electrolysis of sulphuric acid with a lead electrode is too faint to be certain of the color but appears white although the blue would probably come out if the light could be made stronger. When concentrated acid is used the light becomes greenish white, due to a static discharge.

Cadmium sulphate gives the same light during fluorrescence, direct union and electrolysis, the only difference is that in electrolysis the color is a lighter yellow.

Mercurous sulphate gives the same light during electrolysis as the fluorescence but the direct union gives a negative result. This is due probably to the fact that one cannot heat the mercury high enough to make it react with the sulphate group fast enough to give out light.

Zinc oxide gives a green light during fluorescence, during direct union brought about in a stream of oxygen by boiling the metal by means of a blast lamp or during the action of sodium peroxide. The blue light sometimes given out by the action of the sodium peroxide may be due to a second light effect from the sodium peroxide itself.

Cadmium oxide burns with a yellow flame but is not fluorescent.

Arsenic trioxide gives a green light both during fluorescence and direct union of the metal with oxygen, although the light may be blue if the oxygen supply is increased. 
There are three possible sources for the light given out by mercury salts under the cathode rays.

(I) Formation of the mercurous salt by the direct union of the elements.

(2) Formation of the mercuric salt by the direct union of the elements.

(3) Change of the mercurous to the mercuric salt.

It is possible that each of these may give out light and may have its own characteristic color.

By electrolysis with a mercury anode one obtains the mercurous salt and the light due to its formation. By the direct union of the elements one obtains usually the mercuric salt. An attempt was made to heat the mercurous salt in the presence of an excess of the halogen to convert it into the mercuric salt and see if any light was given out during the reaction. But the mercurous salt breaks down so easily and at such a low temperature into a mixture of mercury and the mercuric salt that the temperature could not be raised high enlough to cause the reaction between the halogen and the mercurous salt to go rapidly enough to give out light.

After the mercurous salt breaks up and the temperature is raised the reaction takes place between the halogen and the mercury that has been set free and gives out the light due to this reaction.

\section{Summary}

In this work we have obtained the following results:

(I) There is a definite close relation between chemical action and phosphorescence.

(2) A number of salts prepared by electrolysis give off light during their formation.

(3) A number of salts prepared by the direct union of the metal with the acid radical give off light during their formation.

(4) In the case of sodium and potassium it was shown that the light given out by the slow union with the acid radical is different from that given out by rapid union

(5) The color of phosphorescence and thermo-phosphorescence is the same as that of this slow union. 
(6) In nearly every case the phosphorescent light is of the same color as the light given out by chemical combination.

(7) Some salts said to be phosphorescent were found not to be so when pure.

(8) Some salts which were said not to show decomposition on exposure to cathode rays were found to do so on long exposure.

(9) Some of the salts which did not show phosphorescence were made to do so by the addition of other salts as impurities.

(Io) Cadmium sulphate breaks down upon long exposure to the cathode rays and leaves a residue of the oxide.

(I I) Lead sulphate breaks down in the cathode rays and leaves a residue of finely divided lead.

(i 2) Metathetical reactions, by which a number of these salts were formed in solution, show no ight effect.

(13) The decomposition of some of the salts by metallic sodium showed no light effect.

(I4) The electrolysis of some of the fused alkaline halides with an alternating current showed no characteristic glow like that which Lenard found when these salts were heated on a platinum wire in the flame.

(I5) Sodium peroxide shows fluorescence and phosphorescence under the action of cathode rays if vacuum is maintained by continuous pumping.

(16) The fluorescence of aluminum oxide under the cathode rays is due to the presence of sodium in the form of the peroxide or the aluminate.

This work was suggested by Professor Bancroft and has been carried out under his direction. The author takes this opportunity of expressing appreciation of his many suggestions and generous interest in the work. He also thanks the Department of Physics for the use of apparatus in facilitating the work.

Cornell University,

Iay, rgog 